\title{
Innovative Design and Research into the Talent Cultivation Mode of "Level Certification" under School-Enterprise Cooperation
}

\author{
Yong Wang ${ }^{a}$, Jun Zhou ${ }^{b}$ \\ Chong Qing College of Electronic Engineering, Department of Intelligent manufacturing and \\ Automotive, Chong Qing, China \\ awycowboy@163.com, b4413470@qq.com
}

\begin{abstract}
At present, vocational education is sparing no effort to promote "industry-education integration and school-enterprise cooperation". However, the school-enterprise cooperation has problems such as low degree of participation by enterprises and schools, etc. Therefore, beginning with the practice of talent cultivation mode in a microcosmic way, this thesis raises suggestions on the deep school-enterprise cooperation, proposes establishing the talent cultivation mode of "level certification" under school-enterprise cooperation and applies the mode to practice to provide references to education under school-enterprise cooperation and technical talents under system training.
\end{abstract}

Keywords: School-enterprise Cooperation; Cultivation Mode; Level Certification.

\section{Introduction}

In recent years, higher vocational education of China is developing rapidly. Consequently, its scale and level have been promoted to some degree, besides, the establishment of talent cultivation connotations of higher vocational education is attracting wide attention from various polytechnic colleges. Economic advancement and industrial upgrade give higher vocational education the mission to conduct reform. Therefore, the talent cultivation mode under school-enterprise cooperation becomes necessary to improve higher vocational talent cultivation quality and adapt to social and economic development. In the circumstances, the talent cultivation mode under school-enterprise cooperation is the main cultivation mode adopted by domestic and foreign vocational schools. How to overcome dilemmas in traditional school-enterprise cooperation, face challenges directly and achieve breakthroughs is an urgent problem for the development of new-style cultivation modes under school-enterprise cooperation [1].

\section{Problems and Thinking in School-enterprise Cooperation}

\subsection{Problems in School-enterprise Cooperation}

\subsubsection{Low Enterprise Enthusiasm}

After many years' implementation of school-enterprise cooperation, enterprises don't have enough understanding of school-enterprise cooperation. On the one hand, many enterprises aren't interested in school-enterprise cooperation and they unilaterally think that school-enterprise cooperation will aggravate burden to enterprises, increase enterprise cost and disturb normal business orders; in the meanwhile, under the current situation of oversupply of labor force, middle and small-sized enterprises can easily get a large amount of cheap labor force. On the other hand, in school-enterprise cooperation, the cooperative relations between both parties can be embodied by passive schools [2]. The reason is that normally, it is schools that take the initiative in contacting enterprises. Therefore, in school-enterprise cooperation, generally schools are enthusiastic while enterprises are not so passionate. Consequently, the cooperative relations of both parties are maintained mainly by the relations between the school principals and enterprise leaders. 


\subsubsection{Unfulfilled Policies and Supervision}

At present, relevant laws and regulations on school-enterprise cooperation aren't sound and feasible enough and some local policies are only macro guiding policies. Therefore, they only encourage and advocate school-enterprise cooperation, instead of making it legally necessary. In addition, no any corresponding supervision authority is set up to carry out substantial supervision into both schools and enterprises. As a result, policies on school-enterprise cooperation can't be executed, which influences cooperation results.

At present, school-enterprise cooperation mainly rests on shallow cooperative modes, lacking follow-up momentum. Most school-enterprise cooperation cases mainly stay at the pilot stage of individual specialties and shallow cooperation can't integrate into long-term business plans of enterprises, thus affecting the stability and continuity of cooperation projects. Besides, the phenomena of "one-off" school-enterprise cooperation appear frequently. At the beginning of cooperation, driven by the utilitarian goal, both parties are active, yet blind and impetuous. For example, schools will easily introduce inferior enterprises while enterprises won't truly carry out cooperation projects needed by schools. Consequently, both parties have to terminate the cooperation in advance, resulting in the "one-off" phenomena [3].

\subsubsection{Imperfect Vocational Qualification System}

Vocational qualification system is an important measure for the deep execution of schoolenterprise cooperation. At present, in China, the vocational qualification system isn't perfect, enterprise employment and employee posts are random, which also leads to low motivation of students and in-service staff to learn and to a small number of joint talent cultivation opportunities provided by schools and enterprises.

\subsection{Thinking and Suggestions.}

In combination with the primary problems in school-enterprise cooperation, comprehensive and complete design is demanded for each link from formulation of national polies and regulations macroscopically, dominant control by local authorities and institutions intermediately to execution of talent cultivation modes microscopically. This thesis raises suggestions on the design and innovation in talent cultivation modes microscopically.

\subsubsection{Expand Cooperation ideas}

When seeking school-enterprise cooperation, schools should pay attention to the cooperation with industry leaders and brand enterprises. On the one hand, this kind of enterprises have systematic and standard career planning and strong ability to receive student internship and employment; on the other hand, schools can radiate to the whole industry and various enterprises through platforms of largescale enterprises so as to have opportunities to cooperate with downstream and matching enterprises. Large-scale enterprises have strong ability to conduct scale expansion, therefore, schools can make use of their extensive operating networks to output talents and realize long-term cooperation [4].

Win-win interaction and common development of both schools and enterprises are the basis for cooperative effects. Schools and enterprises should integrate order cultivation, work-integrated learning, substituted post internship and other traditional cooperation ways and make greater efforts to execute extensive and deep cooperation and to develop and design projects that can bring substantial benefits to enterprises: carry out training on new employers of enterprises, develop projects to improve competence of in-service staff, provide technical service training needed by enterprises, participate in the research and development of new technologies of enterprises, jointly establish companies with brad advantages, etc.

\subsubsection{Establish New-style Talent Cultivation Modes}

School students are just like enterprise employees. Therefore, talent cultivation objects should be not only students, but also in-service staff. However, the design of traditional talent cultivation modes only considers school students, instead of enterprise employees. In consequence, if the design of talent 
cultivation modes can take both school students and enterprise employees into consideration at the same time, it will greatly promote the degree of participation of enterprises.

\section{Design of Talent Cultivation Mode of "Level Certification" under School- Enterprise Cooperation}

Even though the grade system of talent cultivation by vocational schools can reflect the gradability of comprehensive abilities, it only involves school students and isn't closely integrated into the stepby-step improvement of abilities of enterprises and social members. The combination between school talents cultivation and in-service employees training is an approach to deep school-enterprise integration. Level-certification talent cultivation mode proposed based on the common characteristics of batches, systematization and continuity of school talent cultivation and enterprise employees training and in combination with school talent cultivation standard, professional qualification standard of industrial association and enterprise technical grade standard reflects the gradability, graduality and continuity talent cultivation and is applicable to both school students cultivation and social member ability promotion training[5].

The criteria for the design of "level certification" talent cultivation mode under school-enterprise cooperation are the unity of three standards, meaning school talent cultivation standard, professional qualification standard of industrial association and enterprise technical grade standard. On this basis, model design should combine specialized course standard and professional standard, teaching process and producing process, academic certificate and professional certificate, academic education and professional qualification as well as in-service training.

\subsection{Level-certification Talent Training System Guarantees the Step-by-Step Improvement of Abilities}

Management systems of various enterprises on employees reflect professional skill levels of the continuous enhancement of abilities. For example, in the management of after-sales service staff in the auto industry, there are gold, silver and copper level training certification and management carried out on the maintenance staff of foreign brands, such as Buick and Cadillac and there are also three, four and five-stars level training certification and management carried out on domestic brand Changan. Low-to-high professional skill levels, corresponding to different professional competence standard, establish the approach to development and advancement for employees.

Professional qualification reflects knowledge, technology and competence necessary to engage in certain profession. In addition, it combines disciplinary knowledge and industry competence and directly reflects the actual competence levels that employees meet, including the assessment of both knowledge and skills. At present, the execution of "two certificates" drives students to combine professional demands and academic education, get familiar with and strengthen knowledge and skill learning related to the specialties in advance, improve professional quality and practice competence and increase employment opportunities. However, in recent years, due to low gold contents, stale examination contents, a lack of scientific authentication means, etc., most professional qualification certificates are getting less and less recognition from enterprises. What's worse, some large-scale enterprises only accept and adopt their internal skill assessment standards and systems. Therefore, how to truly give play to the functions of professional qualification certificates of national, industrial and association levels, make industries approve their value and enable employees to be employed and promoted according to certificates is an urgent problem to be solved for the level-certification talent cultivation mode.

On the basis of the traditional "two certificates" system, the "level-certification" talent cultivation mode introduces enterprise-level certificate. In other words, based on the combination between traditional skill certificates (issued by the country or certain industry associations) and academic certificates (issued by the education commission or other school authorities), "level-certification" talent cultivation mode introduces level certificates (issued by enterprises) to realize the combination of three kinds of the certificates. Firstly, junior, intermediate and senior professional qualification 
certificates and level 1, level 2, level 3 and level 4 enterprise certificates are integrated. For this purpose, the formulation of curriculum standards, design and implementation of contents and other teaching contents and requirements should be carried out by schools and enterprises based on standards of different levels of professional qualification certificates and in combination with enterprise positioning, development directions, new standards and technologies, specific demands for job requirements, etc. to systematically cultivate talents that meet industrial development demands and are accepted by enterprises. At the same time, as for the competence training aiming at in-service enterprise employees and social members, its training contents and certification mode should unify with national or industrial certification standards. In the meanwhile, when obtaining enterprise level certification, enterprise employees can also apply for professional skills certification so as to get professional qualification certificates of corresponding levels, which will not only satisfy the promotion demand of in-service enterprise employees, but also increase employment opportunities for social members.

\subsection{Establish Employee Training Platforms to Achieve Sustainable Improvement of Competence}

How to achieve the integration between talent cultivation and employee training and establish approaches to the sustainable improvement of employee competence is an important link to realize deep industry-education integration and win-win situations for both schools and enterprises. Therefore, it is an innovative measure for the "level certification" talent cultivation mode by combining the level certification promoting training of enterprise employees and student competence cultivation, carrying out talent cultivation activities and forming a co-built, co-managed, shared and win-win school-enterprise cooperative operation system.

To meet the requirements for employee training, the design and content selection of the talent cultivation curriculum system should pay more attention to its practicability. To be more specific, the talent cultivation curriculum system can not only improve theory, but also have the ability to effectively solve practical problems at work; besides, it can not only meet the requirements for current posts, but also be useful for the technological reform and career development of future posts.

The curriculum system under "level certification" talent cultivation mode is featured by the combination between specialized courses under academic education and courses customized by enterprises. Only the real combination between courses and work can facilitate the seamless connection between order talents and enterprise employees. This combination reserves general education courses, specialized core courses, etc. in traditional talent cultivation modes, in the meanwhile, it integrates professional quality training package, know-how training package, overall post capacity improvement package and other practical courses that meet special demands of enterprises. Academic education courses follow traditional course standards and contents while customized courses, based on enterprise products and school-enterprise cooperation, use textbooks jointly developed by both parties and other supporting teaching materials and introduce enterprise projects, cases and up-to-date technologies to achieve the real integration between courses and work.

At the same time, examination-free system is carried out for enterprise employee's cultivation. In accordance with course-exemption conditions for talent cultivation at all levels, enterprise employees can apply for course exemption. Then, the talent cultivation committees of schools and enterprises will have spot or normal check on the application. Once any employee is qualified for course exemption after the check, certificate will be issued to this employee directly who can have training of next level.

\section{Application and Practice of "Level Certification" Talent Cultivation Mode}

Based on the school-enterprise strategic cooperation agreement, from 2013, Chongqing College of Electronic Engineering and China Changan Automobile Group started to carry out level certification joint talent cultivation. They have successively opened two "level certification" talent 
order class to train thousands of students. In this way, level certification talent cultivation mode has been greatly applied and put into practice.

In the customized enterprise courses, enterprises raise course targets and schools and enterprises jointly formulate standards and course contents, develop supporting theory, skill and certification courses and adopt theory-practice integration teaching mode. In combination with the release of new car models by enterprises, schools formulate and update course contents and standards in time, as well as adopt different versions. "Level certification" cultivation order class uses specialized and customized courses while the training aiming at after-sales maintenance employees of Changan Auchan dealers mainly users customized courses.

Talent cultivation teaching group of "level certification" maintenance technicians is constituted by full-time school teachers as well as technical supervisors of business department and key after-sales engineers of Changan Auchan. The trainers are held by full-time school teachers that have passed the training assessment organized by Changan Auchan. The trainers need to regularly participate in training organized by the company, undertake in-store training, answer market problems and undertake other after-sales services. Besides, to meet the requirements for teaching and training, trainers should regularly participate enterprise internships, master new car modes and technologies and figure out typical market problems.

The level certification of Auchan maintenance technicians introduces national professional skill verification standards and carried out the combination between level certification standards and national professional qualification standards. In addition, enterprise training certification management department and national professional skill verification work together to achieve "one examination for two certificates" which are maintenance technician level certificate and professional qualification level certificate.

\section{Conclusion}

Deep school-enterprise cooperation and joint talent cultivation are the effective approaches to actual industry-education integration, maximum corporate profits and optimized school development and the key issue of cooperation is how to integrate major setup and industry links, talent cultivation and employee training, course development and job requirements, classroom teaching and production practice, scientific \& technological research and enterprise innovation, etc. The issue can be solved by establishing "level certification" talent cultivation mode under deep school-enterprise cooperation. Besides, reference significance is brought to cooperation with other vocational schools.

\section{Acknowledgments}

This work was supported by the education science 13th five-year plan program of Chongqing (No. 2017-GX-166), the vocational and technical education association of China Higher Education Society program (No. GZYYB2017012) and research platform program of Chongqing College of Electronic Engineering (NO. XJPT201703).

\section{References}

[1]. Tao Yancheng. Current Situation and Prospect of School-Enterprise Cooperation Talent Cultivation Model in Higher Vocational Education[J]. Vocational Education Forum, 2013 (23): 65-67.

[2]. Liu Gang, Tao Cuixia, Zhai Ji Mei. Investigation and Research on the status quo of school enterprise cooperation. Education in [J]. era, 2015 (20): 13-13.

[3]. Duo Shujie, Yi Xueling. Comparison of School-Enterprise Cooperation in Vocational Education in China and Analysis of Influencing Factors: Based on the Survey of 20 Vocational Schools in China [J]. Vocational and Technical Education, 2015, 36 (25): 48-52. 
[4]. Xiao Fangming. Exploration and Practice of School-Enterprise Cooperation Talent Cultivation Model[J]. China Vocational and Technical Education, 2010 (14): 90-92.

[5]. Liu Jie. Current Situation, Problems and Countermeasures of School-Enterprise Cooperation Talent Cultivation Model in Higher Vocational Colleges [D]. Guangxi Normal University, 2017. 